\title{
A Model of the Kinetics of Insulin in Man
}

\author{
Robert S. Sherwin, Karl J. Kramer, Jordan D. Tobin, Paul A. Insel, \\ John E. Liljenquist, Mones Berman, and Reubin ANDres \\ From the Clinical Physiology Branch, Gerontology Research Center, National \\ Institutes of Child Health and Human Development, National Institutes of \\ Health, The Baltimore City Hospitals, Baltimore, Maryland 21224, and the \\ Laboratory of Theoretical Biology, National Cancer Institute, National \\ Institutes of Health, Bethesda, Maryland 20014
}

A в S T R A C T The design of the present study of the kinetics of insulin in man combines experimental features which obviate two of the major problems in previous insulin studies. (a) The use of radioiodinated insulin as a tracer has been shown to be inappropriate since its metabolism differs markedly from that of the native hormone. Therefore porcine insulin was administered by procedures which raised insulin levels in arterial plasma into the upper physiologic range. Hypoglycemia was prevented by adjusting the rate of an intravenous infusion of glucose in order to control the blood glucose concentration (the glucose-clamp technique). (b) Estimation of a single biological half-time of insulin after pulse injection of the hormone has been shown to be inappropriate since plasma insulin disappearance curves are multiexponential. Therefore the SAAM 25 computer program was used in order to define the parameters of a three compartment insulin model.

The combined insulin mass of the three compartments (expressed as plasma equivalent volume) is equal to inulin space ( $15.7 \%$ body wt). Compartment 1 is apparently the plasma space $(4.5 \%)$. The other two compartments are extra-vascular; compartment 2 is small $(1.7 \%)$ and equilibrates rapidly with plasma, and compartment 3 is large $(9.5 \%)$ and equilibrates slowly with plasma.

The SAAM 25 program can simulate the buildup and decay of insulin in compartments 2 and 3 which cannot be assayed directly. Insulin in compartment 3 was found to correlate remarkably with the time-course of the servo-controlled glucose infusion. Under conditions of a steady-state arterial glucose level, glucose infusion is a measure of glucose utilization. We conclude that compartment 3 insulin (rather than plasma insulin) is a more direct determinant of glucose utilization.

Received for publication 12 September 1973 and in revised form 16 January 1974.
We suggest that the combined use of glucose-clamp and kinetic-modeling techniques should aid in the delineation of pathophysiologic states affecting glucose and insulin metabolism.

\section{INTRODUCTION}

The interrelationships of insulin and glucose metabolism in the intact animal are difficult to define because of two limitations of the usual experimental procedures: (a) direct measurement of insulin secretion cannot be done and $(b)$ direct measurement of insulin concentration at its sites of action is also unachievable. Most studies in man have relied upon measurement of insulin concentration in peripheral plasma, since this can be readily accomplished. Computer modeling of appropriately designed studies can, however, provide prediction for rates of insulin secretion, distribution, and destruction and for the quantity of insulin in body compartments which are not accessible to direct measurement.

Previous studies on the kinetics of insulin have generally measured the rate of disappearance of the hormone after a pulse injection. Estimates of biological half-times of insulin have ranged from 3 to $35 \mathrm{~min}$ (1-10) when a single exponential decay has been assumed. The large variation in these estimates is due primarily to the selection of the time interval chosen for analysis and to the choice of labeled or unlabeled hormone. Izzo, Bartlett, Rancone, Izzo, and Bale (11), in studies on the rat, concluded that insulin disappearance is multiexponential. They were concerned that "the concept [of biologic half-time] will be used because it is convenient and, as a result, will lead to erroneous and insufficiently penetrating interpretation of the data." Silvers, Swenson, Farquhar, and Reaven (12), using bovine $\left[{ }^{181} \mathrm{I}\right]$ insulin and a kinetic analysis, proposed a three compartment model of insulin metabolism in man. 
TABLE I

Clinical Data and Experiments Performed

\begin{tabular}{|c|c|c|c|c|c|c|c|c|c|c|}
\hline \multirow[b]{3}{*}{ Subject } & \multirow[b]{3}{*}{ Age } & \multirow[b]{3}{*}{$\begin{array}{r}\text { Body } \\
\text { wt* }\end{array}$} & \multirow[b]{3}{*}{$\begin{array}{c}\text { Surface } \\
\text { area* }\end{array}$} & \multirow[b]{3}{*}{$\begin{array}{l}\text { Obesity } \\
\text { index* }\end{array}$} & \multirow{3}{*}{$\begin{array}{l}\text { Fasting } \\
\text { plasma } \\
\text { insulin* }\end{array}$} & \multirow{3}{*}{$\begin{array}{l}\text { Fasting } \\
\text { blood } \\
\text { glucose*+ }\end{array}$} & \multirow{3}{*}{$\begin{array}{c}\text { Oral } \\
\text { glucose } \\
\text { tolerance }\end{array}$} & \multicolumn{3}{|c|}{ Number of experiments performed } \\
\hline & & & & & & & & \multirow{2}{*}{$\frac{\begin{array}{c}\text { Single } \\
\text { injection }\end{array}}{(25 \mathrm{mU} / \mathrm{kg})}$} & \multicolumn{2}{|c|}{ Prime + continuous infusion } \\
\hline & & & & & & & & & $\begin{array}{l}\text { Low dose } \\
(1 \mathrm{mU} / \mathrm{kg} / \mathrm{min})\end{array}$ & $\begin{array}{c}\text { High dose } \\
(2 \mathrm{mU} / \mathrm{kg} / \mathrm{min})\end{array}$ \\
\hline & $y r$ & kg & $m^{2}$ & & $\mu U / m l$ & $\mathrm{mg} / 100 \mathrm{ml}$ & $\begin{array}{c}\text { percentile } \\
\text { rank }\end{array}$ & & & \\
\hline R. B. & 18 & 85.4 & 2.09 & 1.12 & 14.8 & 96 & 21 & & 19 & \\
\hline R. D. & 28 & 88.8 & 2.09 & 1.19 & 12.4 & 92 & 38 & & $1 \|$ & \\
\hline W. E. & 31 & 77.9 & 1.91 & 1.18 & 6.0 & 91 & & 1 & 1 & 1 \\
\hline L. F. & 27 & 81.0 & 2.03 & 1.10 & 9.2 & 87 & 90 & 1 & 2 & \\
\hline R. H. & 27 & 76.1 & 1.98 & 1.03 & 9.0 & 94 & & 1 & 1 & \\
\hline W. H. & 24 & 77.6 & 1.97 & 1.06 & 8.0 & 92 & 97 & & 1 & \\
\hline M. J. & 24 & 60.0 & 1.69 & 0.93 & 11.5 & 92 & & 1 & & \\
\hline T. K. & 22 & 79.5 & 1.99 & 1.10 & 10.0 & 89 & 16 & 1 & 1 & 1 \\
\hline R. L. & 27 & 75.4 & 1.92 & 1.08 & 14.8 & 99 & 52 & & 1 & 1 \\
\hline E. L. & 45 & 64.8 & 1.77 & 0.98 & 12.5 & 90 & & & 1 & \\
\hline G. N. & 22 & 84.4 & 2.06 & 1.14 & 17.0 & 95 & & 1 & & \\
\hline M. P. & 23 & 85.0 & 2.07 & 1.15 & 20.0 & 98 & & & & 1 \\
\hline J. R. & 28 & 72.4 & 1.88 & 1.06 & 7.7 & 93 & 30 & & 1 & \\
\hline L. R. & 38 & 90.0 & 2.07 & 1.19 & 14.5 & 100 & & & & 1 \\
\hline W. S. & 34 & 71.2 & 1.85 & 1.05 & 6.4 & 85 & 78 & & 2 & 1 \\
\hline R. W. & 31 & 76.9 & 1.94 & 1.09 & 9.5 & 86 & 87 & & 1 & \\
\hline
\end{tabular}

* Mean value given for each subject.

¥ The modification of the AutoAnalyzer procedure for rapid analysis of glucose in whole blood used in these studies yields results which are $9 \%$ higher than true blood glucose concentration.

\$ See reference 16 .

|| 2-h insulin infusion.

T 3-h insulin infusion.

This form of analysis permits calculation of insulin turnover rates as well as hormone distribution and compartmental exchange rates. Valid use of radioactive tracer requires that the kinetics of the labeled and unlabeled molecule be the same; Genuth (13) has recently questioned such kinetic identity with respect to insulin.

In this study the unlabeled hormone was used to investigate the kinetics of insulin in man. Young male subjects were infused with native porcine insulin; the expected hypoglycemia was prevented by a servo-control glucose infusion. The parameters of a three compartment insulin model were defined by utilizing the SAAM computer program $(14,15)$. Changes in the rate of glucose utilization had no immediate simple temporal relationship to changes in the plasma insulin concentration. However, glucose utilization closely paralleled the time course of insulin levels in a single extravascular model compartment.

\section{METHODS}

Subjects were ambulatory, healthy male volunteers aged 18-45 yr. All subjects were within $20 \%$ of their desirable body $\mathrm{wt}^{1}$ and were consuming weight-maintaining diets of

${ }^{1}$ The middle of the weight range for male subjects of medium frame from the 1959 Metropolitan Life Insurance Company table for desirable weight was used. normal composition. All had negative primary family histories for diabetes mellitus and none had elevated fasting blood sugars. Nine subjects received an oral glucose tolerance test $(1.75 \mathrm{~g} / \mathrm{kg}$ body wt) and were considered normal by an age adjusted nomogram (16) (Table I). A total of 27 studies were performed on 16 subjects who fasted overnight before testing.

A catheter was inserted in a brachial artery for blood sampling and in an antecubital vein for insulin and glucose administration. After a control period of at least $30 \mathrm{~min}$, infusions of crystalline porcine insulin (Eli Lilly and Co., Indianapolis, Ind.) were administered by one of two techniques: (a) a pulse injection of $25 \mathrm{mU} / \mathrm{kg}$ body wt and (b) a prime plus continuous infusion. In the second technique during the $10-\mathrm{min}$ priming period the total insulin infused was twice that infused in subsequent 10 -min intervals. The dose was administered in a logarithmically falling manner until $10 \mathrm{~min}$ when the continuous infusion was begun. The continuous infusion rates were: (a) low dose $(1 \mathrm{mU} / \mathrm{kg}$ body $\mathrm{wt} / \mathrm{min})^{2}$ and (b) high dose $(2 \mathrm{mU} / \mathrm{kg}$ body wt/ $\mathrm{min})$. The total insulin infusion lasted $80 \mathrm{~min}^{3}$ All experiments were continued for an additional $40 \mathrm{~min}$ after the infusion was discontinued. In order to prevent insulin adsorption to glassware and to the plastic infusion apparatus, infusates were prepared with the addition of $2 \mathrm{ml}$ of the subject's whole blood per $50 \mathrm{ml}$ of infusate. Insulin recovery in the infusates averaged $104 \pm 9 \%$ (mean \pm SD).

${ }^{2}$ Certain individuals received a continuous infusion of 40 $\mathrm{mU} / \mathrm{m}^{2}$ body surface area/min; this was virtually identical to $1 \mathrm{mU} / \mathrm{kg} / \mathrm{min}$ infusions in these subjects.

${ }^{8}$ In two studies the infusion period was' extended to 120 and $180 \mathrm{~min}$.

1482 Sherwin, Kramer, Tobin, Insel, Liljenquist, Berman, and Andres 


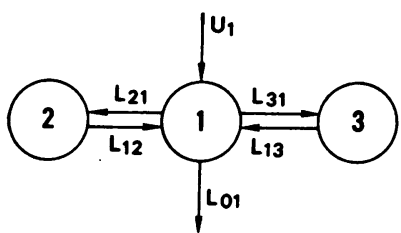

MODEL A

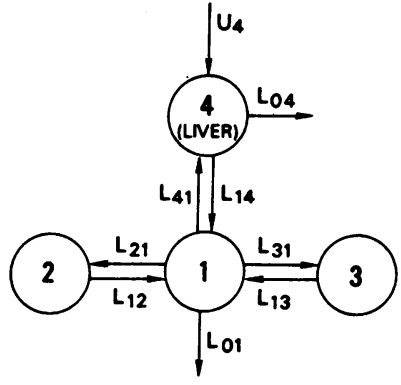

MODEL B

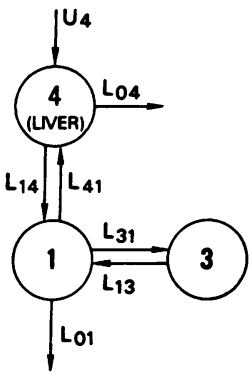

MODEL C

FIGURE 1 Multicompartmental model of insulin. Parameters related to compartment 2, model A are compared to analogous values for compartment 4 , model $\mathrm{C}$.

\begin{tabular}{|c|c|c|c|c|c|c|c|c|c|c|c|c|}
\hline & $\mathrm{L}_{01}$ & & $\mathrm{~L}_{21}$ & $\mathrm{~L}_{12}$ & $\mathrm{~L}_{31}$ & $\mathrm{~L}_{13}$ & $M_{1}^{*}$ & $\mathrm{M}_{2}$ & $\mathrm{M}_{3}$ & $\mathrm{U}_{1 \ddagger}$ & $\mathrm{R}_{01} \S$ & \\
\hline Model A & 0.251 & & 0.142 & 0.394 & 0.042 & 0.020 & 40.5 & 14.4 & 87.7 & 10.2 & 10.2 & \\
\hline Model C & $\begin{array}{c}0.125 \\
L_{01}\end{array}$ & $\begin{array}{c}0.185 \\
\mathrm{~L}_{04}\end{array}$ & $\begin{array}{c}0.268 \\
\mathrm{~L}_{41}\end{array}$ & $\begin{array}{c}0.209 \\
L_{14}\end{array}$ & $\begin{array}{c}0.042 \\
\mathrm{~L}_{31}\end{array}$ & $\begin{array}{c}0.020 \\
\mathrm{~L}_{13}\end{array}$ & $\begin{array}{l}40.5 \\
M_{1}\end{array}$ & $\begin{array}{l}73.7 \\
\mathrm{M}_{4}\end{array}$ & $\begin{array}{l}87.7 \\
\mathrm{M}_{3}\end{array}$ & $\begin{array}{c}18.7 \\
\mathrm{U}_{4}\end{array}$ & $\begin{array}{r}5.1 \\
\mathrm{R}_{01}\end{array}$ & $\begin{array}{l}13.6 \\
R_{04}\end{array}$ \\
\hline
\end{tabular}

* $\mathrm{M}_{j}$, steady-state mass or total amount of insulin in compartment $j(\mathrm{mU})$.

$\ddagger \mathrm{U}_{j}$, steady-state transport of insulin into compartment $j$ from outside the system $(\mathrm{mU} / \mathrm{min})$.

$\S \mathrm{R}_{o i}=\mathrm{L}_{o i} * \mathrm{M}_{i}$ is the rate of insulin-irreversible loss from compartment $i$ in $\mathrm{mU} / \mathrm{min}$.

The glucose-clamp technique was used to maintain each subject at his own basal arterial blood glucose concentration during and after insulin administration. Arterial blood samples were obtained every $5 \mathrm{~min}$ and the blood glucose concentration, measured rapidly by an automated ferricyanide method (Technicon Instruments Corp., Tarrytown, $\mathrm{N}$. Y.), was used in a negative feedback formula to adjust the infusion rate of a $50 \%$ glucose solution.

The details of these periodic computations will be presented in a separate communication now in preparation. Only the principal features of the technique are given here. (a) The glucose analytical delay time (from blood collection to readout of glucose concentration) was $4 \mathrm{~min}$. Each servo-correction of the glucose infusion rate was therefore based upon the subject's arterial glucose concentration 4 min previously. (b) The initial glucose infusion rate was $2.0 \mathrm{mg} / \mathrm{kg}$ body $\mathrm{wt} / \mathrm{min}$ and was started at 4 or $5 \mathrm{~min}$ after the insulin injection or infusion was begun; this dose and starting time were determined empirically. (c) At $10 \mathrm{~min}$ the glucose infusion was increased generally to 3.5 $\mathrm{mg} / \mathrm{kg}$ body $\mathrm{wt} / \mathrm{min}$ in the pulse injection studies, to 2.5 in the low-dose continuous insulin infusion study, and to 3.0 in the high-dose study; these doses were also empirically determined. ( $d$ ) The first servo-correction was made when the $10-\mathrm{min}$ arterial blood glucose concentration became available, i.e., at $14 \mathrm{~min}$. Subsequent corrections were made at 19, 24, $29 \mathrm{~min}$, etc. until the end of the study. Computations for the servo-correction of the glucose infusion were made on a programmable desk calculator; time delay from readout of glucose concentration to resetting of the dial on the continuously variable glucose infusion pump was only a few seconds.

The formula for the servo-correction is based upon the negative feedback principle. Thus, if the actual blood glucose concentration is greater than the goal, the glucose infusion rate is decreased, and vice versa. The details of the actual computation, as we noted, will be presented elsewhere. Of pertinance to this paper is the fact that despite the high insulin levels created by the experimental proce- dures, the arterial glucose concentration was maintained at its basal level within reasonably narrow limits (see Results). Arterial immunoreactive insulin was measured, in duplicate, by a modification of the semiautomated double antibody radioimmunoassay technique of Haas, Shenkman, Weissman, and Andres (17).

\section{MODEL DEVELOPMENT}

A three compartment model was the minimal model necessary to be compatible with both pulse injection and primedcontinuous infusion data in all subjects. Although two compartments appeared adequate in some instances, in others its use was precluded by the presence of systematic deviations. Mean data were used to test the models and to derive estimates for the values of the model parameters.

The following assumptions were introduced concerning the insulin system:

1. Endogenous insulin secretion remains at basal levels throughout each study.

2. Exogenous porcine insulin metabolism is indistinguishable from that of endogenous insulin.

3. Insulin removal over the range studied is first order (linear).

A system is said to be linear if its response to a linear combination of arbitrary time-dependent inputs equals the same linear combination of the individual responses (15). Thus, if the response of the system to an input $U_{1}(t)$ is $r_{1}(t)$ and to an input $U_{2}(t)$ is $r_{2}(t)$, then the response to an input $k_{1} U_{1}(t)+k_{2} U_{2}(t)$ is $k_{1} r_{1}(t)+k_{2} r_{2}(t)$. In analyzing our data, therefore, the basal plasma level was subtracted from the total measured plasma insulin level to obtain the response due to exogenous input. Some tests of the linearity of the system were performed and are discussed later.

Data presented for each individual subject were derived from a simultaneous computer analysis of all studies performed on that subject. Model rate constants were derived 


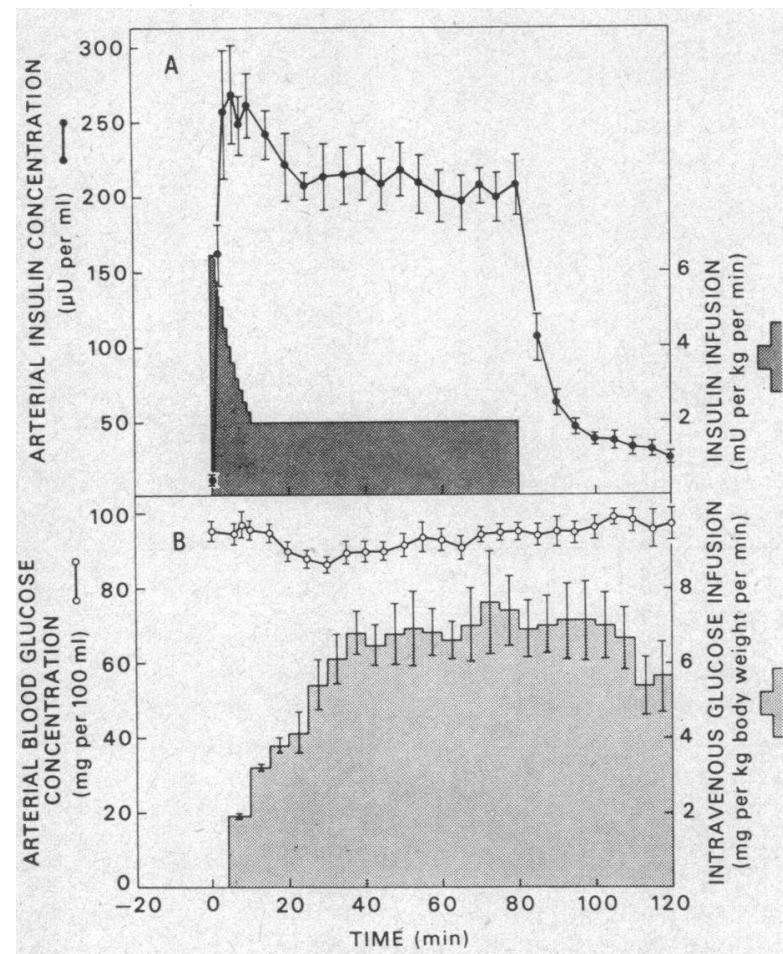

Figure 2 Primed-continuous infusion study. Mean $( \pm \mathrm{SE})$ values for the $2 \mathrm{mU} / \mathrm{kg} / \mathrm{min}$ continuous infusion $(n=6)$. (A) Insulin infusion (shaded area) and resulting arterial plasma insulin concentration. (B) Arterial glucose concentration and the glucose infusion necessary to maintain blood glucose near basal levels.

to satisfy the response data for the various inputs. A single set of values was found to satisfy all the data for the various inputs.

In view of the fact that only plasma concentration data were available, it was not possible to define uniquely the values of all nine pathways in a general three compartmental model (18); and, for simplicity, a parallel model with all losses from the central compartment was assumed (Fig. 1). This will be referred to as "model A."

The fitting of the model to the data was performed on a Univac 1108 digital computer using the SAAM 25 program (14). Starting with initial estimates, parameter values were adjusted by an iterative procedure until a least squares fit was obtained (19).

The results of the data analysis showed that the plasma equivalent volume (PEV) ${ }^{4,5}$ of compartment $1,45 \pm 3 \mathrm{ml} /$ $\mathrm{kg}$ (mean $\pm \mathrm{SD}$ ), was equal to plasma volume as reported by others $(20,21)$. Hence compartment 1 was identified as plasma. Estimates were also derived for the rate constants $\left(L_{i y}\right)^{\circ}$ and the metabolic clearance rate (MCR) (the vol-

- Abbreviations used in this paper: BSDR, basal systemic delivery rate; $\mathrm{MCR}$, metabolic clearance rate; $\mathrm{PEV}$, plasma equivalent volume; $V_{i}$, volume of compartment $i$.

- The plasma equivalent volume of a compartment is the volume that the mass of the compartment would occupy if its concentration were equal to that of plasma.

- The fraction of compartment $j$ delivered per minute to compartment $i$ is denoted by $L_{i j}$; and the fraction irrever- ume of plasma completely and irreversibly cleared of insulin per minute, $\mathrm{L}_{01} \mathrm{~V}_{1}$ ).

In order to calculate basal insulin secretion by the pancreas and steady-state levels (quantities) of insulin in a multicompartment model, the site of entry of newly secreted insulin must be known. We have indicated in model $\mathrm{A}$ that insulin enters compartment 1 , the plasma compartment. Endogenously secreted insulin however traverses the liver before its entry into the systemic plasma compartment. It is estimated that $40-55 \%$ of newly secreted insulin is destroyed on first passage through the liver (22-25) ; furthermore, the liver probably degrades insulin brought to it whether it be newly secreted or recycled through the splanchnic bed or via the hepatic artery. Although a direct effect of insulin level in the portal vein on hepatic extraction ratio is possible, the direction of such an effect, as well as its yery existence, is in dispute $(11,22,25-29)$. To examine the role that liver may have on our model, a value of $47 \%$ was chosen as an estimate of the hepatic destruction of insulin per passage.

It becomes important, in choosing a site of entry for insulin in the model, to know whether any of the exchange compartments in it reflect the liver kinetic process. If one of the compartments does reflect the liver, in whole or in part, a loss path will have to be added to that compartment leading to further modifications of the model.

To gain a better understanding of the role that a liver compartment in the model may play in the interpretation of the data, we expanded model $\mathrm{A}$ to include an additional liver compartment. This is shown as model B in Fig. 1. In model $\mathrm{B}$, newly secreted insulin enters compartment 4 , marked "liver," and $47 \%$ of it is assumed to be degraded by way of $\mathrm{L}_{04}$. Hepatic plasma flow in normals is approximately $840 \mathrm{ml} / \mathrm{min}(30)$ and is represented by $\mathrm{L}_{41}$, expressed as a fraction of compartment $1(0.268 / \mathrm{min})$.

In view of the fact that the data can resolve only three compartments, model B cannot be solved uniquely. Two special cases under which the four compartment model B reduces to a three compartment model are considered.

First, let insulin flow through the liver be rapid and let $47 \%$ of it be destroyed on first passage. This is operationally equivalent to an assumption that $\mathrm{L}_{14}+\mathrm{L}_{04}$ is effectively instantaneous, in which case model $B$ reduces to model A with the interpretation that endogenous insulin enters compartment 1 directly, and its calculated value, which we call the "basal systemic delivery rate (BSDR)," is 53\% of pancreatic secretion. Insulin destroyed by the liver after first passage is interpreted as a loss directly from plasma.

In the second case, the fractional turnover rate of the "liver" compartment ( $\mathrm{L}_{04}+\mathrm{L}_{14}$ ) in model B is assumed equal to that of the rapidly exchanging compartment ( $\left.L_{12}\right)$ in model $\mathrm{A}$. In this case, the parameter values of model $\mathrm{B}$ are related to those of model $A$ in the following way (see reference 18) (superscripts $A$ and $B$ for models $A$ and $B$, respectively):

$$
\begin{aligned}
& \mathrm{L}_{04}{ }^{B}+\mathrm{L}_{14^{B}}{ }^{B}=L_{12}{ }^{A} \\
& \mathrm{~L}_{31}{ }^{B}=L_{31}{ }^{A} \\
& \mathrm{~L}_{13}{ }^{B}=L_{13^{A}} \\
& \mathrm{~L}_{41}{ }^{B}+L_{21}{ }^{B}+L_{01}{ }^{B}=L_{21}{ }^{A}+L_{01}{ }^{A} \\
& L_{01}{ }^{A}-L_{01}{ }^{B}=\left(L_{21}{ }^{A}-L_{21}{ }^{B}\right) \frac{L_{04}{ }^{B}}{L_{14}{ }^{B}}
\end{aligned}
$$

These equations, combined with the fact that $L_{41}=0.268$ / min (fraction of plasma flowing through the liver per unit

sibly lost from the system per minute from compartment $i$ by $L_{o t}$. 
time), result in a unique solution of all parameter values in model $B$. Since the solution yields a value of $\mathrm{L}_{21}{ }^{B} \approx 0$, the model reduces to model $\mathrm{C}$, and the calculated insulin input into compartment 4 is a direct estimate of pancreatic secretion. Since model $A$ and $C$ are readily interchangeable, model $\mathrm{A}$ was used for all the data fitting, and transformations to model $\mathrm{C}$ were made when of interest.

Analysis of the mean data yielded an estimate of PEV for the total insulin system of $157 \mathrm{ml} / \mathrm{kg}$ body wt $( \pm 20$ $\mathrm{SE}$ ), a value comparable to estimates of inulin space (31). It, therefore, seems reasonable that insulin distributes in the extracellular space. Unfortunately, the data from individual studies were not always adequate to define their total PEV with sufficient precision.

In fitting individual studies, therefore, an additional statistical constraint was introduced that the ratio of the total insulin plasma equivalent space $\left(V_{T}\right)$ to PEV of compartment 1 be a constant equal to $( \pm 10 \%)$ the value calculated for the mean population. This constraint can be derived from the relation

$$
\frac{\mathrm{L}_{21} \mathrm{~A}}{\mathrm{~L}_{13} \mathrm{~A}} \mathrm{~V}_{1}+{ }_{\mathrm{L}_{12} \mathrm{~A}^{\mathrm{A}}}^{\mathrm{L}_{2}^{\mathrm{A}}} \mathrm{V}_{1}+\mathrm{V}_{1}=\mathrm{V}_{\mathrm{T}^{\mathrm{A}}}
$$

which leads to

$$
\frac{\mathrm{L}_{31} \mathrm{~A}}{\mathrm{~L}_{13} \mathrm{~A}}+\frac{\mathrm{L}_{21} \mathrm{~A}}{\mathrm{~L}_{12} \mathbf{A}^{\mathrm{A}}}+1=\frac{\mathrm{V}_{\mathrm{T}} \mathrm{A}}{\mathrm{V}_{1}}
$$

In transforming model $\mathrm{A}$ to model $\mathrm{C}$, the total plasma equivalent space for insulin does not remain constant because of the entry of insulin into the nonplasma compartment containing an irreversible loss. The PEV of compartment 1 , however, remains invariant. The constraint introduced for model A carries over to model C by transforming the parameters in accordance with the transformation equations given above.

\section{RESULTS}

Results from the six high-dose prime + continuous insulin infusion studies are shown in Fig. 2. The infusion technique and the arterial insulin curve generated are illustrated in the upper panel (A). After an initial overshoot, insulin levels remained relatively constant for a $1-h$ period. The insulin level achieved was within the physiologic range. Table II summarizes the average insulin values for all studies. The average coefficient of variation for the population was approximately $8.0 \%$. When the infusion was discontinued, the plasma insulin concentration initially fell rapidly and then slowly approached basal levels.

The ability of the glucose-clamp technique to maintain blood glucose concentration at basal levels is illustrated in the lower panel (B). Note that the subjects' arterial glucose concentrations were fixed within narrow limits despite insulin levels which would normally produce severe hypoglycemia. Success of the procedure was judged in terms of accuracy (actual mean glucose concentration $\div$ desired glucose concentration $\times 100$ ) and in terms of stability (the coefficient of variation of glucose concentration during the insulin infusion pe-
TABLE II

Average Insulin Concentrations (20-80 min) during Prime + Continuous Infusions

\begin{tabular}{lccccc} 
& \multicolumn{2}{c}{$\begin{array}{c}\text { Low dose } \\
(1 \mathrm{mU} / \mathrm{kg} / \mathrm{min})\end{array}$} & & \multicolumn{2}{c}{$\begin{array}{c}\text { High dose } \\
(2 \mathrm{mU} / \mathrm{kg} / \mathrm{min})\end{array}$} \\
\cline { 2 - 3 } \cline { 5 - 6 } Subject & Mean & $\mathrm{CV}{ }^{*}$ & & Mean & $\mathrm{CV}^{*}$ \\
\hline & $\mu U / \mathrm{ml}$ & $\%$ & $\mu U / \mathrm{ml}$ & $\%$ \\
R. B. & 110.8 & 5.0 & & \\
R. D. & 116.1 & 7.2 & & \\
W. E. & 91.1 & 9.5 & & 243.3 & 7.9 \\
L.F. & $84.8 \ddagger$ & $7.1 \ddagger$ & & \\
R. H. & 72.6 & 7.6 & & \\
W. H. & 81.5 & 12.7 & & \\
T. K. & 102.2 & 5.7 & & 196.9 & 8.9 \\
R. L. & 92.1 & 7.7 & & 192.5 & 5.9 \\
E. L. & 102.7 & 7.5 & & \\
M. P. & & & & 278.3 & 7.6 \\
J. R. & 89.2 & 7.3 & & 198.7 & 10.5 \\
L. R. & & & & \\
W. S. & $81.5 \ddagger$ & $7.5 \ddagger$ & 158.4 & 8.4 \\
R. W. & 88.6 & 9.3 & & \\
Mean & 92.8 & 7.8 & & 211.4 & 8.2 \\
SD & 12.8 & 2.0 & 42.5 & 1.5 \\
\hline
\end{tabular}

* Coefficient of variation.

$\ddagger$ Mean values for two studies.

riod). In the 27 studies performed the accuracy averaged $97.4 \pm 3.8 \%$ and the stability averaged $3.8 \pm 1.4 \%$ (mean $\pm \mathrm{SD}$ ).

The shaded area in Fig. 2 (B) represents the variable i.v. glucose infusion rate required to maintain euglycemia. Under conditions of a relatively steady-state glucose concentration, the infusion rate provides a measure of the rate of glucose utilization after insulin administration. The results shown in Fig. 2 demonstrate that the time-course of glucose utilization did not parallel changes in plasma insulin concentration. This lag phenomenon was consistently observed both during primed-continuous infusion studies and after a pulse injection.

Data fitting and model parameters. The three compartment model developed (Fig. 1, model A) was able to fit all the data derived from each subject obtained from the diverse experiments described. Fig. 3 illustrates the ability of the computed curve to fit the mean data obtained utilizing both the pulse injection and primedcontinuous infusion protocols. A summary of model parameters obtained from the SAAM program in the 16 subjects is given in Table III.

As discussed, the initial distribution volume (compartment 1) measured $45 \pm 3 \mathrm{ml} / \mathrm{kg}$ (mean $\pm \mathrm{SD}$ ), a value which supports the assumption that compartment 1 represents plasma volume. This value is model independent, i.e., it is the same in both model $\mathrm{A}$ and model $\mathrm{C}$.

A Model of the Kinetics of Insulin in Man

1485 

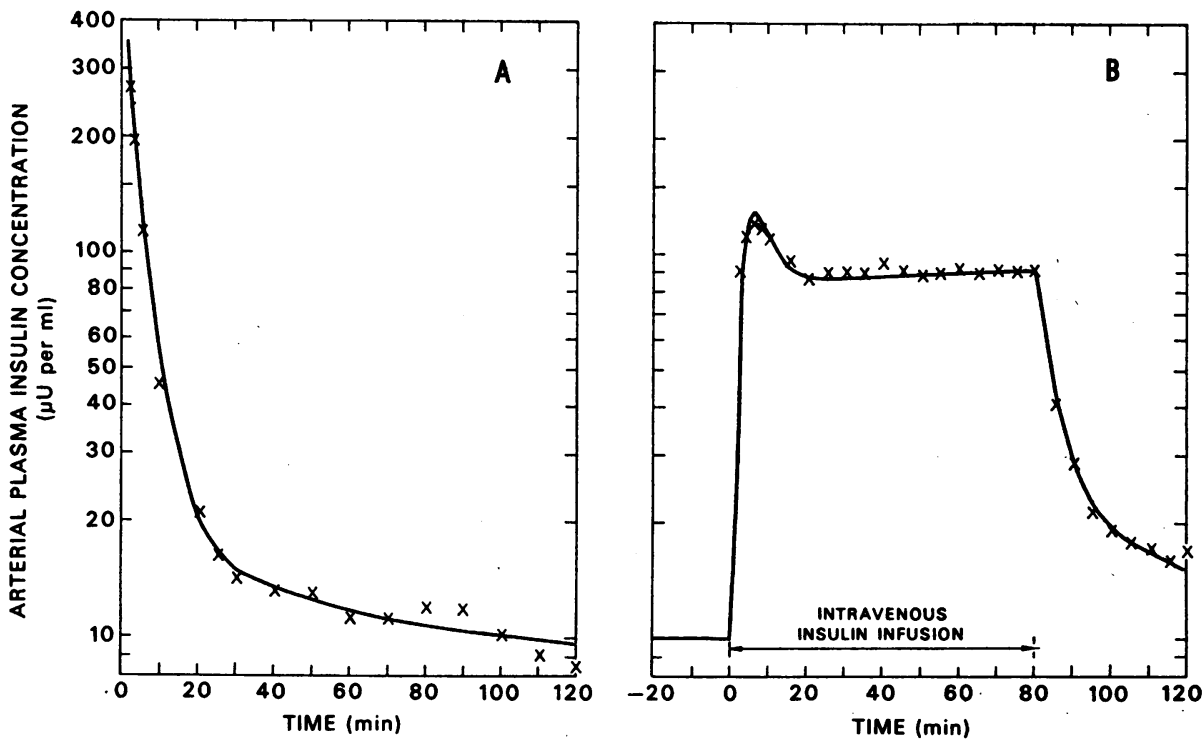

FIGURE 3 Computer matching (solid line) of mean arterial insulin values using the three compartment model. $X=$ measured insulin values. (A) Single injection study $(25 \mathrm{mU} / \mathrm{kg})$. (B) Primed-continuous infusion study $(1 \mathrm{mU} / \mathrm{kg} / \mathrm{min})$. Insulin values are plotted on a logarithmic scale in order to present a 30 -fold range of concentrations with clarity.

The mean time for an insulin molecule in plasma (calculated as $1 /\left[\mathrm{L}_{01}+\mathrm{L}_{21}+\mathrm{L}_{21}\right]$ ) is $2.3 \mathrm{~min}$.

Compartment 2, with a PEV of $17 \pm 6 \mathrm{ml} / \mathrm{kg}$, is in rapid equilibrium with plasma; the mean time of an insulin molecule in this compartment (calculated as $1 / \mathrm{L}_{12}$ ) is $2.5 \mathrm{~min}$. For model $\mathrm{C}$ the equivalent compartment 4 has a $\mathrm{PEV}$ of $88 \pm 25 \mathrm{ml} / \mathrm{kg}$.

On the other hand, compartment 3 has a large PEV $(95 \pm 8 \mathrm{ml} / \mathrm{kg})$ and equilibrates slowly with plasma, the mean time for a molecule in this compartment being $50 \mathrm{~min}$. This value is invariant between models $\mathrm{A}$ and $\mathrm{C}$.

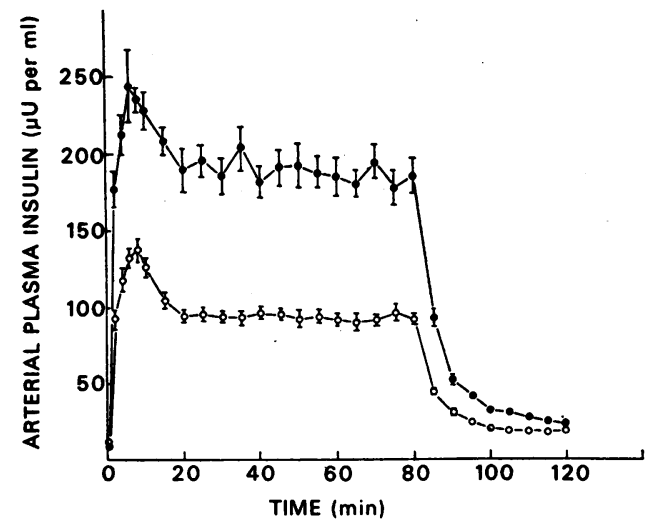

FIGURE 4 Time-course of mean plasma insulin concentrations in eight subjects who received both the 1.0 and 2.0 $\mathrm{mU} / \mathrm{kg} / \mathrm{min}$ primed-continuous infusions. Four of these subjects were the young adults, W. E., T. K., R. L., and W. S.; the other four subjects were older adults (age 57$77 \mathrm{yr}$ ) who were clinically normal volunteers.
The results also indicate that the response of plasma insulin is proportional to the rate of infusion (Fig. 4), and that the same parameter values adequately describe single pulse, constant infusion, and washout kinetics in the same individuals (Fig. 3). This supports the assumption that the insulin system is linear over the range of these studies.

Metabolic clearance rate $(M C R) . \mathrm{MCR}$ was expressed with respect to $\mathrm{m}^{2}$ body surface area. Mean $\mathrm{MCR}$ for all 16 subjects was $451 \pm 74 \mathrm{ml} / \mathrm{min} / \mathrm{m}^{2}$ (mean $\pm \mathrm{SD}$ ) or $780 \pm 128 \mathrm{ml} / \mathrm{min} / 1.73 \mathrm{~m}^{2}$ (Table IV).

Basal systemic delivery rate $(B S D R)$. The term "systemic delivery rate" was used, since model A excludes that portion of total pancreatic secretion removed by the liver before entering the systemic circulation. The average BSDR was $5,000 \pm 1,360 \mu \mathrm{U} / \mathrm{min} / \mathrm{m}^{2}$ or $8,650 \pm 2,350 \mu \mathrm{U} / \mathrm{min} / 1.73 \mathrm{~m}^{2}$ (Table IV). These values correspond to a basal posthepatic release of 12.5 $\pm 4.1 \mathrm{U} /$ day $/ 1.73 \mathrm{~m}^{2}$.

If an assumption of $47 \%$ for the hepatic extraction of insulin is made, then the calculated daily basal pancreatic production of insulin is $23.6 \pm 7.7 \mathrm{U} / 1.73 \mathrm{~m}^{2}$.

Insulin-glucose relationships. Parameter solutions obtained from the SAAM 25 program were used to simulate insulin buildup and decay in compartments not directly measured. Results are illustrated in Figs. 5-7. The curves shown are computer derived based upon a mean composite insulin model for each of the experimental protocols, i.e., single injection and low-dose and high-dose primed-continuous infusions. Each graph 
TABLE III

Parameter Values for Model A

\begin{tabular}{|c|c|c|c|c|c|c|c|c|c|c|c|}
\hline Subjects & $\begin{array}{c}\text { Body } \\
\text { wt }\end{array}$ & $\mathrm{L}_{01}$ & $L_{21}$ & & $\mathrm{~L}_{12}$ & $L_{21}$ & $L_{18}$ & $\mathrm{~V}_{1} *$ & $\mathbf{M}_{1} \ddagger$ & $M_{2 \ddagger}$ & M 27 \\
\hline & kg & $\min ^{-1}$ & $\min ^{-1}$ & & $\min ^{-1}$ & $\min ^{-1}$ & $\min ^{-1}$ & $m l$ & $m U$ & $m U$ & $m U$ \\
\hline R. B. & 85.4 & 0.224 & 0.127 & & 0.435 & 0.031 & 0.013 & 3,759 & 55.6 & 16.2 & 128.2 \\
\hline R. D. & 88.8 & 0.219 & 0.105 & & 0.466 & 0.037 & 0.013 & 3,460 & $\quad 42.9$ & 9.7 & 122.0 \\
\hline W. E. & 77.9 & 0.219 & 0.112 & & 0.274 & 0.034 & 0.016 & 3,472 & 20.8 & 8.6 & 43.9 \\
\hline L. F. & 81.0 & 0.320 & 0.158 & & 0.323 & 0.038 & 0.019 & 3,636 & 33.3 & 16.3 & 68.2 \\
\hline R. H. & 76.1 & 0.311 & 0.153 & & 0.372 & 0.053 & 0.027 & 5,521 & 31.7 & 13.0 & 61.9 \\
\hline W. H. & 77.6 & 0.277 & 0.179 & & 0.349 & 0.062 & 0.035 & 3,731 & 29.9 & 15.3 & 52.4 \\
\hline M. J. & 60.0 & 0.274 & 0.112 & & 0.434 & 0.040 & 0.016 & 2,500 & 28.8 & 7.4 & 72.9 \\
\hline T. K. & 79.5 & 0.238 & 0.159 & & 0.410 & 0.052 & 0.026 & 3,636 & 36.3 & 14.1 & 72.7 \\
\hline R. L. & 75.4 & 0.256 & 0.177 & & 0.362 & 0.048 & 0.025 & 3,484 & 51.3 & 28.5 & 99.1 \\
\hline E. L. & 64.8 & 0.212 & 0.136 & & 0.438 & 0.027 & 0.016 & 3,378 & 42.4 & 13.1 & 72.7 \\
\hline G. N. & 84.4 & 0.268 & 0.104 & & 0.434 & 0.059 & 0.024 & 3,559 & 60.5 & 14.6 & 152.6 \\
\hline M: P. & 85.0 & 0.164 & 0.086 & & 0.483 & 0.036 & 0.014 & 3,636 & 72.8 & 13.0 & 181.8 \\
\hline J. R. & 72.4 & 0.265 & 0.172 & & 0.391 & 0.040 & 0.023 & 3,559 & 27.4 & 12.1 & 47.7 \\
\hline L. R. & 90.0 & 0.220 & 0.155 & & 0.405 & 0.045 & 0.022 & 4,149 & 60.3 & 23.1 & 121.9 \\
\hline W. S. & 71.2 & 0.288 & 0.166 & , & 0.376 & 0.050 & 0.027 & 3,268 & 21.0 & 9.3 & 39.7 \\
\hline R. W. & 76.9 & 0.264 & 0.166 & & 0.345 & 0.024 & 0.012 & 3,584 & 33.7 & 16.3 & 65.0 \\
\hline Mean & 77.9 & 0.251 & 0.142 & & 0.394 & 0.042 & 0.021 & 3,520 & 40.5 & 14.4 & 87.7 \\
\hline SD & 8.2 & 0.041 & 0.030 & & 0.055 & 0.011 & 0.007 & 334 & 15.4 & 5.3 & 42.0 \\
\hline Mean FSD & & 0.066 & 0.282 & & 0.272 & 0.220 & 0.202 & & & & \\
\hline SD of FSD & & 0.020 & 0.108 & & 0.091 & 0.081 & 0.065 & & & & \\
\hline
\end{tabular}

* Volume of compartment 1.

$\ddagger \mathrm{M}_{j}=$ steady state mass or total amount of insulin in the basal state in compartment $j$.

$\S$ These values represent the mean Fractional Standard Deviation (SD of $L_{i j}$ ) $/ L_{i j}$ of the 16 subjects.

also includes the mean glucose infusion rates required to maintain euglycemia (the shaded area). This area approximates the rate of peripheral glucose utilization during the various experiments. It is evident that the rate of glucose utilization parallels the level of insulin in compartment 3 under all experimental conditions (Figs. 5-7). Furthermore, compartment 3 has a definite time delay in its response compared to compartments 1 and 2 .

\section{DISCUSSION}

The present study demonstrates that a multicompartmental model is necessary to describe the kinetics of insulin in man and that three compartments are adequate to fit all the data from diverse experimental protocols.

The model was initially assumed to be linear with the idea that if nonlinearities were significant we would see them as discrepancies in the fit when analyzing simultaneously the wide variety of kinetic data collected in studies on single individuals: basal state, single pulse, continuous infusion, washout after loading, and, in some individuals, studies at two levels of the administered material. A number of individuals had a combination of such studies, and we did not see any significant pattern
TABLE IV

Insulin Turnover

\begin{tabular}{lcccc}
\hline Subject & $\begin{array}{c}\text { Surface } \\
\text { area }\end{array}$ & $\begin{array}{c}\text { Basal } \\
\text { insulin* }\end{array}$ & MCR & BSDR \\
\hline & $m^{2}$ & $\mu U / m l$ & $m l / m i n / m^{2}$ & $\mu U / m i n / m^{2}$ \\
R. B. & 2.09 & 14.8 & 403 & 5,966 \\
R. D. & 2.09 & 12.4 & 363 & 4,499 \\
W. E. & 1.91 & 6.0 & 402 & 2,413 \\
L. F. & 2.03 & 9.2 & 571 & 5,254 \\
R. H. & 1.98 & 9.0 & 554 & 4,982 \\
W. H. & 1.97 & 8.0 & 525 & 4,201 \\
M. J. & 1.69 & 11.5 & 406 & 4,663 \\
T. K. & 1.99 & 10.0 & 434 & 4,336 \\
R. L. & 1.92 & 14.8 & 464 & 6,846 \\
E. L. & 1.77 & 12.5 & 405 & 5,057 \\
G. N. & 2.06 & 17.0 & 463 & 7,871 \\
M. P. & 2.07 & 20.0 & 289 & 5,777 \\
J. R. & 1.88 & 7.7 & 503 & 3,873 \\
L. R. & 2.07 & 14.5 & 442 & 6,403 \\
W. S. & 1.85 & 6.4 & 511 & 3,271 \\
R. W. & 1.94 & 9.5 & 484 & 4,594 \\
Mean & 1.96 & 11.5 & 451 & 5,000 \\
SD & 0.12 & 4.0 & 74 & 1,360 \\
\hline
\end{tabular}

* Mean of at least two values.

A Model of the Kinetics of Insulin in Man

1487 


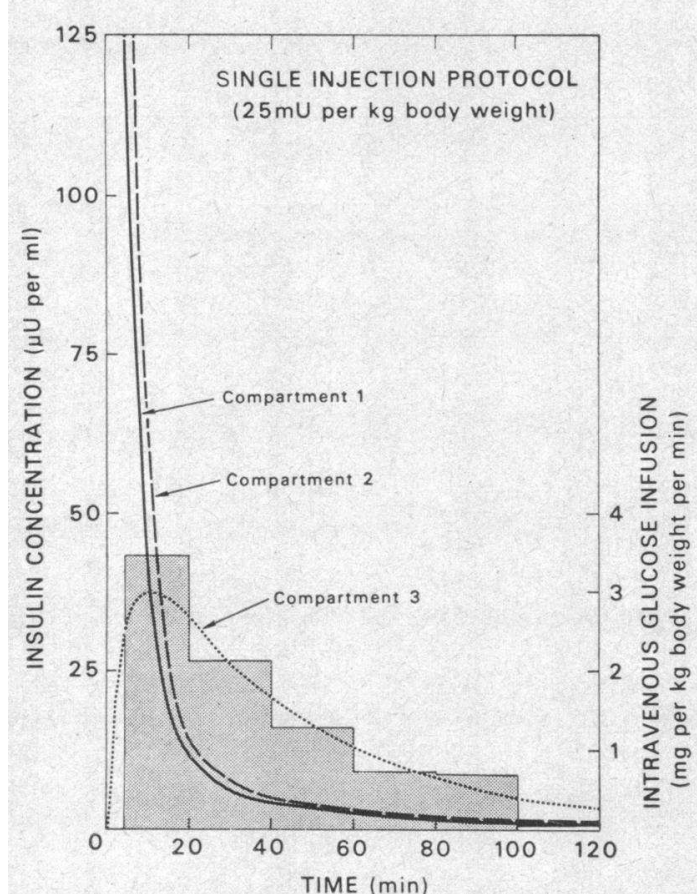

FIgURE 5 Computer-derived estimates of insulin levels in model compartments for the single injection experiments. The shaded area represents the amount of glucose infused (mean) to maintain the subjects' basal arterial glucose concentration.

of inconsistencies arise from the fit of the data to challenge the validity of linearity. It can be seen from the definition of linearity given earlier that a carefully designed series of tests is required to prove the linearity of a system, and even then it is only to within the resolution and accuracy of the data. Obviously, we have not carried out a full set of such tests. Our experiments, however, do serve in part as tests of linearity, and what we can say is that over the range of levels tested and within the resolution and accuracy of our data we did not find it necessary to introduce nonlinearities in the model.

Endogenous insulin secretion was assumed to remain constant during the exogenous infusion studies. The glucose-clamp technique, by maintaining euglycemia, minimizes factors known to affect insulin secretioneither directly through changes in blood glucose concentration, or indirectly, through the activation of counterregulatory mechanisms. Studies of direct feedback inhibition of insulin release by insulin have yielded conflicting data (32-36). Unfortunately, the insulin radioimmunoassay could not distinguish between the porcine and endogenous insulin. Although recent reports have suggested that plasma C-peptide levels might be used as a measure of endogenous production (37), a sensitive assay was not available for present experiments.
With respect to model $\mathrm{A}$, the mean total PEV of 157 $\mathrm{ml} / \mathrm{kg}$ is similar to that of inulin space (31) and suggests an extracellular distribution for insulin. Yet model $\mathrm{A}$ is only one version of the more general model $\mathrm{B}$. Even though the extreme models ( $\mathrm{A}$ and $\mathrm{C}$ ) are both compatible with the data, the total PEV is larger (233 $\mathrm{ml} / \mathrm{kg}$ ) in the latter. A PEV larger than inulin space could arise if insulin has an extravascular concentration greater than plasma, or if insulin is bound to special extravascular sites, such as membranes.

Differences in the rate at which model compartments 2 and 3 equilibrate with compartment 1 might be due to differences in equilibration rates between two interstitial fluid compartments and plasma. These differences may be a function of perfusion efficiency, so that organs with a large blood flow relative to their interstitial volume, e.g. heart, kidney, liver, and gut, may equilibrate rapidly; on the other hand, those tissues that are relatively poorly perfused, such as muscle, adipose tissue, and skin, may have slow equilibration rates. Alternatively, regional differences in capillary permeability could be a significant factor limiting insulin exchange. Even though electron microscopy has clearly demonstrated that capillary morphology is highly variable, evidence that permeability is a function of histologic structure is at present indirect (38-40). However, in support of this possibility, studies on dogs have shown that insulin equilibration in paw lymph is delayed with respect to hepatic and thoracic duct lymph (41). Still another factor that could account for observed differences in equilibration rates is the affinity of insulin for its binding sites in the various tissues. This field is under active investigation in a number of laboratories at this time.

Muscle and adipose tissue comprise approximately $50 \%(42)$ and $15 \%$ (43) of total body wt. If the extracellular water content of muscle and adipose tissue is $17 \%$ (44) and $8 \%$ (43) of their respective weights, then the interstitial volume of these tissues would be $97 \mathrm{ml} / \mathrm{kg}$ body wt. This estimate is similar to the calculated PEV of the large, slowly equilibrating model compartment $3(95 \pm 8 \mathrm{ml} / \mathrm{kg})$.

Compartment 2, which is in rapid equilibrium with plasma, may represent organs which are well perfused and have a rapid exchange with plasma, such as heart, kidneys, gut, and liver. In model $\mathrm{C}$, the rapidly equilibrating compartment 4 is defined as liver only. Independent data on hepatic insulin kinetics, at present unavailable, could distinguish between the alternative models.

The MCR derived from these studies was $780 \mathrm{ml} / \mathrm{min} /$ $1.73 \mathrm{~m}^{2}$, a value which compares well to the $861 \mathrm{ml} / \mathrm{min}$ recently reported by Genuth (13) and to the approximately $900 \mathrm{ml} / \mathrm{min}$ which can be calculated from data

1488 Sherwin, Kramer, Tobin, Insel, Liljenquist, Berman, and Andres 
published by Sönksen, Srivastava, Thompkins, and Nabarro (45). Unlabeled insulin was used in all these investigations. Genuth (13) also used ${ }^{12} I$-labeled porcine insulin and obtained an MCR of $227 \mathrm{ml} / \mathrm{min}$, which is comparable to the value calculated from the report of Stern, Farquhar, Silvers, and Reaven (46) also using the labeled hormone.

Another estimate of the MCR can be made by summing independently derived estimates of clearance rates for various tissues. It has been estimated that renal plasma insulin clearance is $190 \mathrm{ml} / \mathrm{min}$ (47). Hepatic insulin clearance can be computed to be about $400 \mathrm{ml} /$ min. This estimate is based upon a $47 \%$ hepatic extraction of insulin, hepatic plasma flow of $57 \mathrm{ml} / 100 \mathrm{~g}$ liver/ $\min (30)$, and liver wt of $1,500 \mathrm{~g}$. Peripheral tissue insulin clearance can be approximated to be $130 \mathrm{ml} / \mathrm{min}$. This estimate is based upon a peripheral plasma flow of $660 \mathrm{ml} / \mathrm{min}(48)$ and peripheral insulin extraction of $20 \%$. This peripheral extraction value is a rough average of the estimates of $13 \%$ made by Butterfield, Garratt, and Whichelow (49), of $25 \%$ as seen in Fig. 1 of the paper by Rasio, Whichelow, Butterfield, and Hicks (50), and of $20 \%$ cited by Rabinowitz, Langs, Klassen, and Zierler (51).

Thus these three major clearance sites (kidney, liver, and peripheral tissues) might account for $720 \mathrm{ml} / \mathrm{min}$. This sum agrees well with the value of $780 \mathrm{ml} / \mathrm{min}$ for insulin clearance in this study, especially since there are undoubtedly additional minor sites of insulin degradation. The agreement among the investigations using unlabeled insulin and the sum of the independently estimated degradation rates supports the contention of Genuth that values of MCR derived from unlabeled insulin are closer to the correct value for endogenous human insulin than those derived from studies using labeled hormone (13).

Silvers et al. have previously proposed a three compartment series model based on studies using bovine $\left[{ }^{181} \mathrm{I}\right]$ insulin (12). Our data can be fit equally well to either a series or parallel model, as the two cannot be differentiated mathematically at this time. When the model parameters reported by Silvers and his group were

TABLE V

Comparison of Intercompartmental Rate Constants

\begin{tabular}{lccccc}
\hline & $\mathrm{L}_{01}$ & $\mathrm{~L}_{21}$ & $\mathrm{~L}_{12}$ & $\mathrm{~L}_{21}$ & $\mathrm{~L}_{13}$ \\
\hline & & & $\min ^{-1}$ & & \\
$\begin{array}{l}\text { Present study } \\
\begin{array}{l}\text { Silvers, Swenson, } \\
\text { Farquhar, and } \\
\text { Reaven (12)* }\end{array}\end{array}$ & 0.251 & 0.142 & 0.394 & 0.042 & 0.021 \\
& 0.047 & 0.115 & 0.119 & 0.063 & 0.015
\end{tabular}

* Published results converted to parameters of a comparable parallel model.

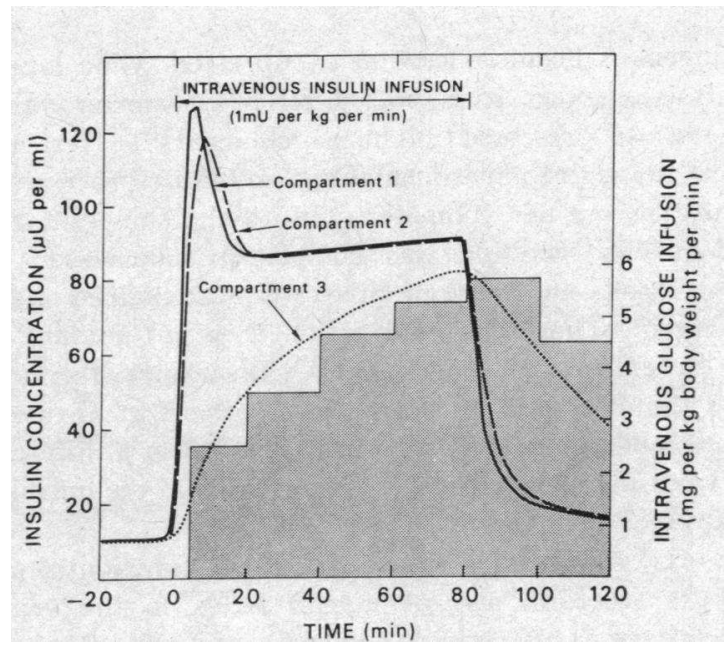

Figure 6 Computer-derived estimates of insulin levels in model compartments for the primed-continuous infusion experiments $(1 \mathrm{mU} / \mathrm{kg} / \mathrm{min}$ insulin infusion $)$.

mathematically converted to their equivalents in a parallel model and compared to values reported in the present study, the major difference (Table V) was that their $\mathrm{L}_{13}$ and $\mathrm{L}_{01}$, respectively, were three and five times slower than our results. This is consistent with the finding of Genuth (13), as noted above, concerning the difference in magnitude of MCR derived from studies using labeled and unlabeled molecules and suggests that there is a difference in the metabolism of the radioactively iodinated and the unlabeled hormone.

On the other hand, the difference in the calculated values of the rate constants between the tracer (labeled) and tracee (unlabeled) experiments may be due to the assumption that endogenous insulin secretion remains unchanged during the tracee experiments. If, in fact,

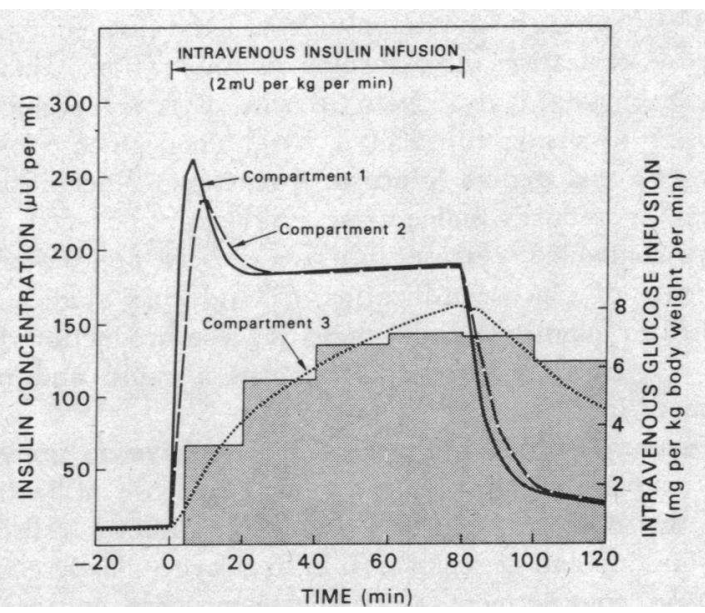

FIGURE 7 Computer-derived estimates of insulin levels in model compartments for the primed-continuous infusion experiments $(2 \mathrm{mU} / \mathrm{kg} / \mathrm{min}$ insulin infusion).

A Model of the Kinetics of Insulin in Man 
endogenous insulin secretion is supressed while kinetic analysis assumes it is not, different parameter values than those presented might be obtained. To test this effect the entire experimental and modeling process was simulated on the computer with the assumption that endogenous secretion was completely suppressed; but these results and those of Silvers et al. remained widely divergent. Thus, this explanation does not account for the difference in our results. We do believe, therefore, that the discrepancies derive from Silvers et al. use of tracer and our use of tracee and are due to a difference between the metabolism of $\left[{ }^{151} I\right]$ insulin and the unlabeled hormone.

Portal vein insulin concentration is a function of pancreatic secretion and of insulin levels in the venous effluent from the spleen, stomach, and gut. The pancreas, according to our model, contributes $16,300 \mu \mathrm{U} /$ min to the portal vein under basal conditions. If portal vein plasma flow is $600 \mathrm{ml} / \mathrm{min}$ (30), then the pancreas can account for $27.2 \mu \mathrm{U} / \mathrm{ml}$ of the insulin concentration in the portal vein. If we assume that no significant loss occurs from gut capillaries, then arterial insulin concentration is equal to that in the venous effluent. As our subjects had a mean fasting arterial insulin level of $11.5 \mu \mathrm{U} / \mathrm{ml}$, the basal portal vein insulin concentration can be estimated as $38.7 \mu \mathrm{U} / \mathrm{ml}$, a value which agrees well with direct measurements in man of $36.9 \mu \mathrm{U} / \mathrm{ml}$ (52).

The estimate that mean BSDR is $12.5 \mathrm{U}$ insulin/day assumes that the mean basal arterial insulin concentration of $11.5 \mu \mathrm{U} / \mathrm{ml}$ is maintained over the entire $24-\mathrm{h}$ period. This estimate compares well with the recent estimates of $12 \mathrm{U}$ made by Genuth (13) and of $14 \mathrm{U}$ made by Turner, Grayburn, Newman, and Nabarro (53).

The glucose-clamp technique used in our studies permits estimation of the magnitude and the time-course of glucose utilization after insulin administration. Glucose uptake by total body equals the sum of $(a)$ the glucose infusion necessary to maintain basal blood glucose levels and $(b)$ endogenous glucose production. Since insulin markedly reduces endogenous production (54-56), the servo-controlled glucose infusion closely approximates the rate of glucose utilization. $\left[{ }^{14} \mathrm{C}\right]$ glucose studies designed to quantitate endogenous glucose production during the clamp experiments confirm a rapid and pronounced insulin inhibitory effect. ${ }^{7}$

Plasma insulin levels were found to have no immediate temporal relation to the rate of glucose utilization. On the contrary, glucose utilization directly reflected the buildup and decay of insulin in a large, slowly equilibrating compartment, a compartment that appears to represent the interstitial fluid of muscle and adipose tis-

\footnotetext{
${ }^{7}$ Unpublished results from this laboratory.
}

sue. The results serve to emphasize the limitations inherent in analyses which relate rapidly changing plasma insulin and glucose levels to physiological mechanisms, for example, the use of the G/I ratio as an index of insulin effect on glucose metabolism.

Our results indicate that kinetic modeling is a powerful tool in the investigation of the insulin system in man. Application of this method to the study of alterations in glucose-insulin interactions which occur with age as well as to the investigation of diabetes mellitus, obesity, uremia, and other states of disordered insulin-glucose relationships might well provide further insight into the mechanisms of the disturbances in these diverse conditions.

\section{ACKNOWLEDGMENTS}

We thank Mrs. Elizabeth Bannon for her technical assistance, Mr. Roland Schnick for the illustrations, and Mmes. Annette L. Watts and Monika Trotta for their secretarial assistance.

\section{REFERENCES}

1. Rasio, E. A., C. L. Hampers, J. S. Soeldner, and G. F. Cahill, Jr. 1967. Diffusion of glucose, insulin, and Evans blue protein into thoracic duct lymph of man. J. Clin. Invest. $46: 903$.

2. Ørskov, H., and N. J. Christensen. 1966. Disappearance rate of exogenous human insulin. Lancet. 2: 701.

3. Ørskov, H., and N. J. Christensen. 1969. Plasma disappearance rate of injected human insulin in juvenile diabetic, maturity-onset diabetic and nondiabetic subjects. Diabetes. 18: 653.

4. Tomasi, T., D. Sledz, J. K. Wales, and L. Recant. 1967. Insulin half-life in normal and diabetic subjects. Proc. Soc. Exp. Biol. Med. 126: 315.

5. Martin, F. I. R., A. E. Stocks, and M. J. Pearson. 1967. Significance of disappearance-rate of injected insulin. Lancet. $1: 619$.

6. Stimmler, L. 1967. Disappearance of immunoreactive insulin in normal and adult-onset diabetic subjects. Diabetes. 16: 652 .

7. Stimmler, L., K. Mashiter, G. J. A. I. Snodgrass, B. Boucher, and M. Abrams. 1972. Insulin disappearance after intravenous injection and its effect on blood glucose in diabetic and non-diabetic children and adults. Clin. Sci. (Oxf.). $42: 337$.

8. Horton, E. S., C. Johnson, and H. E. Lebowitz. 1968. Carbohydrate metabolism in uremia. Ann. Intern. Med. $68: 63$.

9. Williams, R. F., R. E. Gleason, and J. S. Soeldner. 1968. The half-life of endogenous serum immunoreactive insulin in man. Metabolism (Clin. Exp.). 17: 1025.

10. Berson, S. A., R. S. Yalow, A. Bauman, M. A. Rothchild, and $\mathrm{K}$. Newerly. 1956. Insulin- $\mathrm{I}^{131}$ metabolism in human subjects: demonstration of insulin binding globulin in the circulation of insulin treated subjects. J. Clin. Invest. 5 : 170.

11. Izzo, J. L., J. W. Bartlett, A. Rancone, M. J. Izzo, and W. F. Bale. 1967. Physiologic processes and dy-

1490 Sherwin, Kramer, Tobin, Insel, Lilienquist, Berman, and Andres 
namics in the disposition of small and large doses of biologically active and inactive ${ }^{131} \mathrm{I}$-insulins in the rat. J. Biol. Chem. 242 : 2343.

12. Silvers, A., R. S. Swenson, J. W. Farquhar, and G. M. Reaven. 1969. Derivation of a three compartment model describing disappearance of plasma insulin- ${ }^{131} \mathrm{I}$ in man. J. Clin. Invest. 48: 1461.

13. Genuth, S. M. 1972. Metabolic clearance of insulin in man. Diabetes. 21: 1003.

14. Berman, M., and M. F. Weiss. 1967. SAAM Manual. U. S. Public Health Service Publication No. 1703. U. S. Government Printing Office, Washington, D. C.

15. Brownell, G. L., M. Berman, and J. S. Robertson. 1968. Nomenclature for tracer kinetics. Int. J. Appl. Radiat. Isot. $19: 249$.

16. Andres, R. 1971. Aging and diabetes. Med. Clin. North Am. 55: 835 .

17. Haas, M. L., L. Shenkman, P. Weissman, and R. Andres. 1970. A semiautomated technic for radioimmunoassay. Double antibody assay of insulin. Diabetes. 19: 127.

18. Berman, M., and R. L. Schoenfeld. 1956. Invariants in experimental data in linear kinetics and the formulation of models. J. Appl. Physiol. 27: 1361.

19. Berman, M., E. Shahn, and M. F. Weiss. 1962. The routine fitting of kinetic data to models: a mathematical formalism for digital computers. Biophys. J. 2: 275.

20. Henschel, A., O. Mickelsen, H. L. Taylor, and A. Keys. 1947. Plasma volume and thiocyanate space in famine edema and recovery. Am. J. Physiol. 150: 170 .

21. Gregersen, M. I., and J. L. Nickerson. 1950. Relation of blood volume and cardiac output to body type. $J$. Appl. Physiol. 3 : 329.

22. Samols, E., and J. A. Ryder. 1961. Studies on tissue uptake of insulin in man using a differential immunoassay for endogenous and exogenous insulin. J. Clin. Invest. $40: 2092$.

23. Mortimore, G. E., and F. Tietze. 1959. Studies of the mechanism of capture and degradation of insulin-I'si by the cyclically perfused rat liver. Ann. N. Y. Acad. Sci. 82: 329.

24. Madison, L. L., B. Combes, R. H. Unger, and N. Kaplan. 1959. The relationship between the mechanism of action of the sulfonylureas and the secretion of insulin into the portal circulation. Ann. N. Y. Acad. Sci. $74: 548$.

25. Field, J. B. 1972. Insulin extraction by the liver. Handb. Physiol. Sect. 7 (Endocrinol.). 1: 505.

26. Kaplan, N., and L. L. Madison. 1959. Effects of endogenous insulin secretion on the magnitude of hepatic binding of $\mathrm{I}^{181}$ labeled insulin during a single transhepatic circulation in human subjects. Clin. Res. 7: 248.

27. Madison, L. L., and N. Kaplan. 1958. The hepatic binding of $\mathrm{I}^{181}$-labeled insulin in human subjects during a single transhepatic circulation. J. Lab. Clin. Med. 52: 927.

28. Waddell, W. R., and K. E. Sussman. 1967. Plasma insulin after diversion of portal and pancreatic venous blood to vena cava. J. Appl. Physiol. 22: 808 .

29. Marshall, A., R. L. Gingerich, and P. H. Wright. 1970. Hepatic metabolism of insulin in vitro: Clin. Res. 18: 3.3
30. Greenway, C. V., and R. D. Stark. 1971. Hepatic vascular bed. Physiol. Rev. 51: 23.

31. Chesley, L. C., M. Gaudino, M. I. Rubin, P. L. Calcagno, and M. A. Krupp. 1961. Extracellular body water: Man. Part I. Constant infusion technique. In Biological Handbooks, Blood and Other Body Fluids. D. S. Dittmer, editor. Federation of American Societies for Experimental Biology, Washington, D. C. 355.

32. Malaisse, W. J., F. Malaisse-Lagae, P. E. Lacy, and P. H. Wright. 1967. Insulin secretion by isolated islets in presence of glucose, insulin and anti-insulin serum. Proc. Soc. Exp. Biol. Med. 124: 497.

33. Grodsky, G. M., D. L. Curry, L. L. Bennett, and J. J. Rodrigo. 1968. Factors influencing different rates of insulin release in vitro. In Mechanism and Regulation of Insulin Secretion. R. Levine and E. F. Pfeiffer, editors. Acta Diabetol. Lat. 5(Suppl. 1): 140.

34. Sodoyez, J. C., F. Sodoyez-Gouffaux, and P. P. Foà. 1969. Evidence for an insulin-induced inhibition of insulin release by isolated islets of Langerhans. Proc. Soc. Exp. Biol. Med. 130: 568.

35. Iversen, J., and D. W. Miles. 1971. Evidence for a feedback inhibition of insulin on insulin secretion in the isolated, perfused canine pancreas. Diabetes. 20: 1 .

36. Rappaport, A. M., S. Ohira, J. A. Coddling, G. Emprey, A. Kalnins, B. J. Lin, and R. E. Haist. 1972. Plasma insulin feedback on insulin output. Endocrinology. $91: 168$.

37. Rubenstein, A. H., M. B. Block, J. Starr, F. Melani, and D. F. Steiner. 1971. Proinsulin and C-peptide in blood. Diabetes 21 (Suppl. 2) : 661 .

38. Mayerson, H. S., C. G. Wolfram, H. H. Shirley, Jr., and K. Wasserman. 1960. Regional differences in capillary permeability. Am. J. Physiol. 198: 155.

39. Bennett, H. S., J. H. Luft, and J. C. Hampton. 1959. Morphological classifications of vertebrate blood capillaries. Am. J. Physiol. 196: 381.

40. Majno, G. 1965. Ultrastructure of the vascular membrane. Handb. Physiol. (Circ.). 3 : 2293.

41. Rasio, E. A., E. Mack, R. H. Egdahl, and M. G. Herrera. 1968. Passage of insulin and inulin across vascular membranes in the dog. Diabetes. 17: 668.

42. Shohl, A. T. 1939. Mineral metabolism. Monograph 82. Reinhold Publishing Corporation, New York. 19.

43. Brožek, J., F. Grande, J. T. Anderson, and A. Keys. 1963. Densitometric analysis of body composition: Revision of some quantitative assumptions. Ann. N. Y. Acad. Sci. 110: 113.

44. Talso, P. J., N. Spafford, and M. Blaw. 1953. Metabolism of water and electrolytes in congestive heart failure. I. Electrolyte and water content of normal human skeletal muscle. J. Lab. Clin. Med. 41: 281.

45. Sönksen, P. H., M. C. Srivastava, C. V. Thompkins, and J. D. N. Nabarro. 1972. Growth-hormone and cortisol responses to insulin infusion in patients with diabetes mellitus. Lancet. 2: 155.

46. Stern, M. P., J. W. Farquhar, A. Silvers, and G. M. Reaven. 1968. Insulin delivery rate into plasma in normal and diabetic subjects. J. Clin. Invest. 47: 1947.

47. Chamberlain, M. J., and L. Stimmler. 1967. The renal handling of insulin. J. Clin. Invest. 46: 911.

48. Wade, O. L., and J. M. Bishop. 1962. Cardiac Output and Regional Blood Flow. F. A. Davis Co., Philadelphia. 91.

A Model of the Kinetics of Insulin in Man

1491 
49. Butterfield, W. J. H., C. J. Garratt, and M. J. Whichelow. 1963. Peripheral hormone action: studies on the clearance and effect of $\left.{ }^{[181} \mathrm{I}\right]$ iodo-insulin in the peripheral tissues of normal, acromegalic, and diabetic subjects. Clin. Sci. (Oxf.). $24: 331$.

50. Rasio, E., M. J. Whichelow, W. J. H. Butterfield, and B. H. Hicks. 1972. Insulin fixation and glucose uptake by forearm tissues in response to infusions of physiological amounts of insulin in non-diabetic subjects. Diabetologia. $8: 244$.

51. Rabinowitz, D., H. Langs, G. A. Klassen, and K. L. Zierler. 1965. Uptake of insulin by forearm muscle and adipose tissue. Clin. Res. 13: 332.

52. Blackard, W. G., and N. C. Nelson. 1970. Portal and peripheral vein immunoreactive insulin concentrations before and after glucose infusion. Diabetes. 19: 302.

53. Turner, R. C., J. A. Grayburn, G. B. Newman, and
J. D. N. Nabarro. 1971. Measurement of insulin delivery rate in man. J. Clin. Endocrinol. Metab. 33: 279.

54. Steele, R., J. S. Bishop, A. Dunn, N. Altzuler, I. Rathgeb, and R. C. de Bodo. 1965. Inhibition by insulin of hepatic glucose production in the normal dog. $\mathrm{Am}$. J. Physiol. 208: 301.

55. Madison, L. L., B. Combes, R. Adams, and W. Strickland. 1960. The physiological significance of the secretion of endogenous insulin into the portal circulation. III. Evidence for a direct immediate effect of insulin on the balance of glucose across the liver. J. Clin. Invest. 39 : 507.

56. Reaven, G. M., and J. W. Farquhar. 1969. Steady state plasma insulin response to continuous glucose infusion in normal and diabetic subjects. Diabetes. 18: 273. 